\title{
UN EPISODIO BIOGRÁFICO DE LARRA, CRITICO TEATRAL, EN LA TEMPORADA DE 1834
}

\author{
A mi maestro \\ don Alonso Zamora Vicente
}

\section{Propósito de este trabajo EN RELACión CON ESTUdios BIOGRÁFICOS ANTERIORES}

Me propongo aclarar, con nuevos datos, algunos aspectos biográficos de Larra relacionados con su vida profesional en el ambiente de los teatros madrileños de su tiempo. Se trata de ciertos incidentes que alborotaron el mundillo teatral -un tanto revuelto por entonces- que gira en torno a los escenarios de la Cruz y del Príncipe por el año 1834, cuando se preparan los estrenos de nuevos dramas románticos y la ópera italiana apasiona a los aficionados madrileños. Me refiero a un episodio hasta ahora mal conocido, en el que Fígaro, crítico teatral de la Revista Española, se enfrentó con un actor, Agustín Azcona, hasta el punto de desafiarlo a duelo. Fue la temporada en que, tras gran expectación, se presentó en Madrid la cantante italiana Giuditta Grisi ${ }^{1}$, aquel verano del cólera, entre la proclamación del Estatuto Real (15 de abril), el estreno de La conjuración de Venecia (23 de abril) y del Macias (24 de septiembre). Para Larra es una época de profunda crisis y un punto crucial en su obra literaria.

Las fuentes que utilizo son los testimonios contemporáneos que he hallado repasando periódicos de la época: la Revista Española $\mathrm{y}$, en especial, ciertos artículos aparecidos en el Seminario Teatral a fines de mayo y principios de junio de 1834, que hasta la fecha

1 Siempre que se trata de estos artículos de Larra sobre la cantante italiana surge el problema de escribir su nombre. Aunque parece que debe escribirse Giuditta Grisi, Larra se refiere siempre a ella como Judith Grissi o la señora Grissi. He adoptado la primera forma, pero respeto la que aparece en citas textuales. Sigo el mismo procedimiento con los nombres de óperas italianas. En los textos españoles uso la ortografía actual. 
han permanecido fuera del alcance de los biógrafos de Larra. De la Revista, a cuya redacción pertenecía Larra, aporto algunos textos suyos que todavía se encuentran enterrados y sin identificar en las viejas colecciones del periódico ${ }^{2}$.

Las primeras noticias sobre estos incidentes se deben a Ismael Sánchez Estevan. Las dio a conocer en 1917 en un artículo de la Ilustración Española y Americana; años después las incorporó, con muy ligeras modificaciones, al texto de su "ensayo biográfico" sobre Larra ${ }^{3}$. Sus fuentes eran los artículos sobre las representaciones de ópera firmados por Figaro en la Revista Española de mayo a setiembre de 1834; dos artículos de la Gaceta de los Tribunales (3 y 4 de junio de 1834), escritos por Ventura de la Vega en defensa de su amigo Larra contra los insultos que el actor Agustín Azcona le había inferido en el Semanario Teatral; y un artículo, "Personalidades", aparecido el 5 de junio de 1834 en la Revista Española (en adelante $R E$ ), sin firma, pero indudablemente la Larra, en el que se reproducía la conversación sostenida por él con Azcona para exigirle la retractación pública de sus insultos o que los sostuviera en el campo de honor ${ }^{4}$.

Es de suponer que, para entender la defensa de Ventura de la Vega y la conversación reproducida por Figaro, los lectores estarían al corriente de los ataques del actor. Precisamente esos detalles eran los que el biógrafo de Larra no tenía a su alcance. Tuvo que completar por su cuenta, como su imaginación le dio a entender, las piezas que faltaban del rompecabezas. El conocimiento parcial de las fuentes lo llevó a interpretaciones un tanto aventuradas de los hechos. En ellas, las alusiones a la Grisi adquieren un relieve preponderante, añadiendo así una nota más de romanticismo a la vida

2 Cito los artículos de Larra recogidos en libro por la edición de sus Obras, ed. C. Seco Serrano, $B A E$, ts. 127-130. El número romano indica el tomo, el arábigo la página. Para los textos no coleccionados, remito al número correspondiente de la Revista Española. Salvo indicación contraria, los subrayados en las citas son del original.

3 "De una vida romántica, Larra y la Grissi", Ilustración Española y Americana, 11 de febrero de 1917, y Mariano José de Larra (Figaro). Ensayo biográfico redactado en presencia de numerosos antecedentes desconocidos y acompañado de un catálogo completo de sus obras, Madrid, 1934. Casi todas las referencias a Sánchez Estevan pertenecen a este libro, las páginas van en el texto entre paréntesis. IEA indica el artículo de la Ilustración Española y Americana.

4 Los artículos de crítica operística publicados con la firma de Figaro se hallan en la edición citada de Seco Serrano. Fueron coleccionados por primera vez en el Postfígaro, t. 2, de E. Cotarelo, Madrid, 1918. Sánchez Estevan los incluyó en el apéndice II de su obra. También reprodujo en el mismo apéndice los dos artículos de la Gaceta de los Tribunales y el de la Revista Española, titulado "Personalidades". Cuando citemos pasajes de estos tres últimos artículos, desde ahora remitimos a ese apéndice. 
del escritor: "el perfume de una historia de amor" -y de despechocon madrigales amorosos filtrados en la prosa de la crítica teatral, libelos y hasta la amenaza de un duelo para defender el honor de la mujer ultrajada ${ }^{5}$. A pesar de ello, la biografía de Sánchez Estevan significó un avance decisivo después del embarullado e interesante trabajo de Carmen de Burgos ${ }^{6}$. Pero muchos de los misterios que aparecían en ambos libros quedaban sin resolver satisfactoriamente. En un ilustrativo artículo (publicado a raíz del "ensayo biográfico" de Sánchez Estevan), F. Courtney Tarr ${ }^{7}$ expuso un nutrido repertorio de cuestiones que todavía quedaban por considerar o por aclarar. La mayoría ha quedado en el mismo estado de esbozo o de sugerencia en que las dejó Tarr a su temprano fallecimiento. Entre ellas, las relaciones personales de Larra con sus colegas -amigos y enemigos- en el periodismo. Según Tarr (pp. 97-98), ni siquiera sus amistades puramente literarias (Bretón, Ventura de la Vega, Mesonero Romanos, etc.) son tan importantes para la historia detallada de su vida y obras como las vicisitudes de sus relaciones personales y profesionales con propietarios y directores de periódicos, editores, actores y gente de teatro en general, censores, críticos, políticos, etc.

Las relaciones de Larra con Azcona y con la cantante de ópera Giuditta Grisi quedaban entre los problemas no resueltos satisfactoriamente por Sánchez Estevan. Con los pocos datos que obtuvo sobre estas relaciones, se dejó llevar por la inclinación de ver en Larra sobre todo una vida romántica, profundamente afectada por "un visible desequilibrio sentimental, parecido en ocasiones al que más adelante inspiró La Confesion d'un enfant du siècle de Musset" (144).

También F. C. Tarr se sintió atraído por el "genuino temperamento romántico" de Larra y creyó que los datos que se podrían añadir a su biografía no harían más que confirmar "ese cuadro de Larra el hombre, Larra el romántico" (art. cit., p. 108). Aunque acepta como válido el método biográfico de Sánchez Estevan (su interés "en el drama espiritual visto en el juego del detalle biográfico y la autorrevelación literaria", ibid., p. 92), recomienda, sin embargo, que se utilice "con más cuidado y de manera más total" (loe. cit.). Las interpretaciones de Sánchez Estevan a veces iban demasiado lejos en esta dirección. Esto es lo que ocurrió con

5 Dice Sánchez Estevan: "a través de críticas, libelos y desafíos percibimos el perfume de una historia de amor que acaso nos interesa más por lo mismo que aparece vagamente bosquejada, imprecisa, dejando margen a la imaginación para reconstruir a su gusto la pretérita realidad..." (113).

- Carmen de Burgos (Colombine), Figaro (revelaciones, "ella" descubierta, epistolario inédito), Madrid, 1919.

7 "More light on Larra", $H R, 4$ (1936), 89.110. 
el asunto de Larra, la Grisi y Azcona. Ya Garmen de Burgos, al referirse a este episodio después del artículo de Sánchez Estevan en la Ilustración, sin desvirtuar la imagen romántica de Larra, escribe: "Algunos han creído ver en esto un enamoramiento de Fígaro y las manifestaciones de su despecho. Pero dada su galantería de siempre y la justeza de sus apreciaciones, no se puede colegir de todo esto más que una admiración de Fígaro hacia la Grisi, sin duda más como mujer que como artista, desde un principio; pero su espíritu crítico se sobrepone a su admiración para hacer justicia" (op. cit., p. 142) ${ }^{8}$.

Materiales concernientes a este episodio -que Sánchez Estevan no pudo encontrar en las bibliotecas españolas-, se hallan en la Biblioteca de la Universidad de Toronto, gracias al legado del benemérito profesor Milton A. Buchanan. Los ofrezco aquí como contribución a la biografía de Larra que todavía está por escribirse ${ }^{9}$.

\section{Larra y la Grisi, Según I. SÁnchez Estevan: UNA historia de amor}

\section{La actuación de la Grisi en Madrid y el entusiasmo de Larra}

Primero de mayo de 1834, cartelera del teatro de la Cruz: presentación en Madrid de la famosa cantante italiana Giuditta Grisi con la reposición de la ópera del maestro Bellini $I$ Capuleti ed $i$ Montecchi. Eșa misma noche, después de la función, el mordaz Figaro que, según creía equivocadamente Sánchez Estevan, nunca hasta entonces había escrito nada de crítica operística, toma la pluma con entusiasmo y, antes de que se cierre la edición del periódico, escribe arrebatadamente unas líneas como testimonio directo de su admiración por la cantante, dejando los pormenores para el número siguiente (I, 389-391). “Era el entusiasmo artístico exclu-

8 La opinión de F. C. Tarr sobre el asunto es básicamente la misma que la de Colombine: "Uncertain as are the circumstances of Larra's alleged 'infatuation' with Grisi, it is evident from his articles of operatic criticism that his enthusiasm for the artist, like his previous devotion to the Queen, was at least colored by his admiration for the beatiful woman" (art. cit., p. 104). Y aunque no conocía los datos que doy en este trabajo, indica: "It is by no means certain that Larra's enthusiasm for Grisi reaches the point of actual infatuation with her and infidelity (if only sentimental) to the absent Dolores" (ibid., nota 62).

9 Estamos convencidos de que no llegará a escribirse adecuadamente hasta que no se realicen otros trabajos de búsqueda, como éste, pero de más envergadura. En este sentido, hay que hacer constar la importante contribución de Gregorio C. Martín con su reciente libro Hacia una revisión critica de la biografia de Larra; nuevos documentos, Porto Alegre, 1975. 
sivamente?", se pregunta retóricamente Sánchez Estevan. Y responde: "Huyamos de afirmaciones rotundas en materias tan delicadas y sin una prueba plena; pero sinceramente hemos de decir que, leyendo con atención el artículo, parece que no. Tanto como el arte admira Larra la hermosura de la cantante" (99).

El entusiasmo de Larra por la Grisi no cede durante las sucesivas actuaciones de la cantante, si bien la severidad acostumbrada del crítico se manifiesta respecto a las obras y a los demás intérpretes. La Grisi vuelve a cantar el 17 de mayo en Anna Bolena, de Donizetti: "La interesante Ana Bolena que nos ha traído atinadamente la empresa y que a nosotros nos satisface más que la misma de Donizetti" (I, 399b). El $1^{\circ}$ de julio, Norma, otra ópera de Bellini: "nos pareció una aurora de libertad después de diez años de despotismo. Por lo que a nosotros toca, venga el cólera en buen hora, si nos ha de encontrar oyendo a la señora Grissi" (I, $414 b$ ). (En estas palabras percibe Sánchez Estevan resonancias de las expresiones apasionadas del protagonista del Macias, que iba a estrenarse dos meses después; 107).

E1 17 de julio ocurre la matanza de los frailes. El 21 vuelve a actuar la Grisi en La sonnambula, de Bellini. Artículo breve de Larra, como para salir del paso en la "atmósfera pérfida y abrumadora en que nos hallamos envueltos" (I, 419b). Sánchez Estevan (107) no deja, sin embargo, de percibir un madrigal dirigido a la cantante: "Parece escrita [la ópera] para el lucimiento del tenor; y, sin embargo, lució más en ella la señora Grissi; verdad es que es difícil brillar más que ella a su lado" (loc. cit.). De su actuación en la ópera siguiente, Parisinn d'Este, de Donizetti, estrenada el 27 de agosto, dice: "La señora Grissi es la expresión misma, es el amor desesperado, es el entusiasmo frenético del músico y del poeta" (I, 434b). Sánchez Estevan apostilla que del crítico también (108) .

Pero todo se derrumba de repente con La Straniera, de Bellini, presentada el 18 de setiembre y reseñada por Larra en el periódico del día 20. Comienza el artículo: "Una de las más terribles pruebas a que sujeta el Destino al mérito es a vivir demasiado". Si la Grisi hubiera terminado sus actuaciones en Madrid antes de cantar La Straniera, habría pasado "como un brillante meteoro, que deja tras de sí un rastro inmenso de plácida luz. Su vida filarmónica en nuestros teatros hubiera durado poco; pero su memoria no se hubiera acabado nunca [...] Más valía, efectivamente, que se hubiera dicho: "¿Qué lástima!», que no, «QQué chasco!»" (I, 440a-b). Para Sánchez Estevan estas palabras nacen del despecho: "Del mismo modo que los entusiásticos elogios a la belleza de la cantante nos hicieron sospechar en el primer artículo que no eran exclusivamente artísticos los entusiasmos de Larra, las enrevesadas razo- 
nes de éste nos hacen pensar también que muchas de las censuras, más que juzgar a la artista, quieren herir a la mujer" (110-111).

Los supuestos “incidentes de la representación de «Ana Bolena»"

Sánchez Estevan apoya su interpretación de los artículos de Larra sobre la Grisi como reflejo de una historia de amor, en lo que él llama "los incidentes de la representación de Ana Bolena" (IEA), la segunda actuación de la cantante en Madrid. Supone el biógrafo que "el artículo de Larra sobre Ana Bolena, publicado en la $R e$ vista Española el 19 de mayo, y los entusiasmos del crítico por la cantatriz originaron un incidente del que, si queda testimonio indudable, no tenemos todos los detalles que quisiéramos" (102). Ahora tenemos esos detalles, que no sustentan la interpretación de Sánchez Estevan. Ni el artículo de Figaro sobre Anna Bolena, ni sus elogios entusiastas a la cantante tuvieron importancia decisiva en los incidentes.

Sánchez Estevan conocía cierta quintilla alusiva a Larra y a la Grisi, publicada originariamente por Azcona en el Semanario Teatral a raíz de los elogios del crítico sobre la actuación de la cantante en la ópera de Donizetti, y reproducida, para vergüenza del actor, en el primero de los dos artículos que, en defensa de Larra, escribió Ventura de la Vega en la Gaceta de los Tribunales. Conocida fuera de contexto, al biógrafo le parecía una pieza decisiva del rompecabezas que trataba de componer. Decía así:

Un Holofernes no marra.

Tres siglos ha te mató, y hoy, por más que diga Larra, caes bajo la cimitarra que a Holofernes degolló ${ }^{10}$.

"Tan a pechos tomó Larra el asunto -comenta Sánchez Estevan- y tanto le escocieron los agravios personales que, relacionados con la Grissi, le infería Azcona, que fue a desafiarle, y se creyó obligado a reproducir en Ja Revista Española, el 5 de junio, la conversación que había sostenido con el cómico, quien se negó a darle explicación alguna y a batirse con él, a pesar de los esfuer-

10 Comenta Sánchez Estevan: "Esto es, en prosa vil: el poeta (?), dirigiéndose a la auténtica Ana Bolena, degollada tres siglos atrás por un Holofernes, el rey Enrique VIII de Inglaterra, afirma que la desventurada, al cabo del tiempo, ha vuelto a ser degollada, esta vez metafóricamente, por la cimitarra de quien mató a Holofernes, esto es, el arte de Judith, por más que diga Larra, que tanto la elogió" (103). 
zos hechos por Figaro para obligarle a una de las dos cosas" (104). Larra fue a desafiar a Azcona por los agravios que éste le había inferido, pero esos agravios no estaban relacionados con la Grisi.

Larra, en la conversación sostenida con el cómico para pedirle explicaciones (reproducida en $R E$ ), se había referido concretamente a la "multitud de alusiones injuriosas y de calumnias" dirigidas a él en un artículo aparecido en el Semanario Teatral sobre el drama de Víctor Ducange, El Colegio de Tonnington, traducido por Bretón de los Herreros. De ahí, y de lo que decía Ventura de la Vega en sus dos escritos, dedujo Sánchez Estevan, erróneamente, que la quintilla formaba parte del artículo sobre el drama de Ducange que fue la ocasión inmediata del incidente más grave, pues, por lo que en él decía Azcona, Larra se vio obligado a pedirle explicaciones y a desafiarlo a duelo. Siguiendo este encadenamiento de conjeturas, era natural creer que las alusiones de la quintilla, dirigidas a Anna Bolena (la Grisi) y a Larra, se referían a los insultos y calumnias expresados por Azcona en el artículo sobre El Colegio de Tonnington, y, por lo tanto, tales insultos y calum. nias no podían menos que aludir a las relaciones amorosas del crítico con la cantante. "La orientación del artículo -aventura el biógrafo- parece dibujarse en esa prosaica quintilla; la alusión a Larra y a la Grissi no se disimula. Pero el artículo, ¿qué decía?" (103). Esta es la pregunta clave que vamos a contestar luego. En todo caso la orientación del artículo no podía deducirse de la quintilla: como luego veremos, en ese artículo ni aparecía la quintilla, ni se decía nada referente a la crítica de Larra sobre la interpretación de Anna Bolena, ni se aludía en absoluto a la Grisi.

Hacía semanas que Azcona venía lanzando punzadas en su Semanario Teatral a Figaro y a la nueva empresa de teatros que había prescindido de sus servicios. Entre las punzadas se hallaba la quintilla, algunas alusiones a la actuación de la Grisi (adquisición de la nueva empresa) y a los juicios de Larra, crítico teatral partidario de la administración recién inaugurada. Larra y sus amigos respondían a su vez burlonamente, pero sin que la sangre llegara al río. En efecto, la tensión no alcanzó mayores consecuencias hasta que no llegaron los insultos del artículo de Azcona sobre El Colegio de Tonnington, sin que en ellos -insistimosse mezclaran las faldas.

\section{EL EPISodio a LA LUZ DE NUEvos DATOS}

\section{Inauguración de la temporada: la nueva empresa de teatros}

"Después de largos años de asedio, por fin ha tomado una empresa posesión de los teatros de esta Corte" (I, 36la). Así comien- 
za Figaro, el $1^{\circ}$ de abril de 1834, su primera crítica de la temporada teatral inaugurada dos días antes en el Príncipe con una comedia de Bretón, Un novio para la niña, o la casa de huéspedes, y en la Cruz con dos comedias de Scribe: Siempre, traducida por Larra, y Carolina, por Bretón. La nueva empresa empezaba dando entrada a su propio equipo.

Los teatros de Madrid, administrados en temporadas anteriores por el ayuntamiento, volvían por fin a la dirección artística de don Juan de Grimaldi. Larra venía abogando por esta medida desde que empezó a escribir de teatros en $R E$. En enero de 1833 parecía que la cosa ya estaba hecha. La empresa y el ayuntamiento habían llegado a un acuerdo y sólo faltaba la ratificación real del convenio ${ }^{11}$. En contra de los rumores que circulaban por los corrillos, la nueva empresa se proponía dar realce a las representaciones de ópera ${ }^{12}$ e incluso llegó a tener apalabrada a una de las cantantes más famosas del momento, Giulietta Grisi, hermana de Giuditta ${ }^{13}$. Pero el acuerdo entre la empresa y el ayuntamiento no se llevó a cabo. Después de mucha expectativa -anuncia $R E$, 26 de marzo de 1833- el ayuntamiento tomó los teatros a su cargo (I, 194b). La temporada fue de mal en peor. La compañía de ópera, contratada tarde y apresuradamente para que pudiera cantar con ocasión de la jura de la princesa Isabel ${ }^{14}$, un desastre ${ }^{15}$. A los actores se les paga con retraso y por ello se limitan a cumplir sin

11 Leemos en la Revista Española, núm. 21, 15 de enero de 1833: "E1 Rey Nuestro Señor se ha dignado aprobar por Real orden del 8 del corriente las condiciones convenidas entre el Exmo. Ayuntamiento y Don Juan de Grimaldi, a fin de tomar éste a su cargo la empresa de los teatros de esta corte por cinco años, que darán principio el próximo domingo de Pascua de Resurrección".

12 El redactor de teatros de la Revista Española (núm. 23, 22 de enero, 1833) sale en defensa del nuevo empresario: "Sabemos que por algunas gentes se hace circular la especie de que en la próxima temporada cómica se trata de suprimir en los teatros de esta capital la compañía de ópera italiana. Esto es enteramente falso; el nuevo empresario tiene por una de las condiciones que ha estipulado la obligación expresa de continuar con la ópera, efecto de la acertada previsión del gobierno, que conoce haberse esta circunstancia convertido en una especie de necesidad teatral. Por otra parte, la nueva empresa es demasiado ilustrada para intentar que el público no siga disfrutando de una diversión que le es tan favorita. De consiguiente, en la próxima temporada cómica, podemos comunicar que habrá ópera italiana, y diremos que ésta no podrá menos de ser buena, si la empresa (como es de creer) consulta sus intereses".

13 Véanse $R E$, núms. 47 y 49,16 y 23 de ahril de 1833 .

14 Véase $R E$, núm. 49, y los núms. 58, 24 de mayo y 63, 11 de junio.

15 Véanse especialmente las críticas del redactor de $R E$ a las representaciones de las óperas I Normanni a Pariggi, del maestro Mercadante (núm. 79, 23 de julio) y L'Elisir d'Amore, del maestro Donizetti (núm. 84, 9 de agosto). También el comentario sobre la reorganización de la compañía de ópera, en el núm. 129, 10 de diciembre. 
el menor entusiasmo: “CCómo podría ser de otra manera cuando la mayor parte de ellos tienen que emplear el tiempo en buscar fuera del teatro los medios de subsistencia de que los priva la inexactitud que, de algún tiempo a esta parte, se nota en el pago de las nóminas?" ( $R E$, núm. 135, 24 de diciembre de 1833). El Gobierno ha tenido que nombrar una comisión real para que examine la situación y proponga soluciones. Larra insiste en encargar la dirección a una empresa particular (ibid.). A principios de 1834 dice en $R E$, núm. 145, 17 de enero: "Parece ser ya seguro que los teatros de esta capital serán desde la temporada próxima, regidos por empresa particular. Esta circunstancia será necesariamente muy favorable para ellos y de consiguiente para el público [...]. Definitivamente, una empresa hábil y bien conducida puede contribuir mucho a sacar a los teatros del abatimiento en que se encuentran, y esto es probablemente lo que va a suceder". Esta vez parece que va en serio. Los planes de la nueva empresa son ambiciosos. Se propone renovar la escena sin escatimar gastos y con grandes pretensiones artísticas, tanto en el montaje de las obras como en su calidad literaria; romper la rutina fomentando las tendencias modernas del teatro español y dando a conocer las obras más avanzadas del extranjero, es decir, del romanticismo francés. Pero hay que empezar por el teatro nacional. Trae en cartera dos dramas históricos sensacionales: La conjuración de Venecia y Macias, el primero nada menos que del presidente del Consejo de Ministros y el segundo del crítico teatral más acreditado del momento. También algo muy nuevo de Bretón - hasta ahora sólo conocido por sus típicas comedias de costumbres-, un "drama de imaginación" titulado Elena. Esto significa una apertura: tanto Macias como Elena habían sido prohibidas por la censura la temporada anterior ${ }^{16}$. Entre los nuevos autores de la empresa estaban Espronceda y Ros de Olano, y entre los nuevos actores, la joven Matilde Díez. En cuanto a la ópera, intentará llevar a cabo los planes frustrados la última temporada. Si este año no puede traer a Giulietta Grisi, traerá a su hermana Giuditta, famosa entonces como ella, tanto por su voz como por su belleza. Claro que para realizar estos proyectos había que quitar el lastre dejado por la empresa municipal y eliminar a los que mangoneaban en la administración anterior entre ellos, Agustín Azcona, segundo actor cómico y director de escena de la ópera.

Con estos arreglos pronto se forman dos partidos, el de la nueva empresa - los renovadores, la juventud literaria- y el de la oposición. Según anuncia el Semanario Teatral (núm. 1, p. 29), los

16 Véase Correo de las Damas, núms. 22 y 23, 27 de noviembre y 4 de diciembre de 1833. 
de la oposición intentan abrir un nuevo teatro con una compañía "compuesta de individuos excluidos de la Cruz y el Príncipe". Los partidarios de la empresa la apoyan en sus periódicos: Larra en la Revista Española, Ventura de la Vega en la Gaceta de los Tribunales, Bretón en El Universal y en La Abeja. Al comenzar las representaciones, escribe Larra: "Antes de ayer se dio principio a la nueva temporada cómica: es fuerza confesar que es grande el celo de la nueva empresa. Dejando aparte la compañía de ópera que nos tiene preparada, acerca de la cual guardaremos silencio hasta que la experiencia, confirmando nuestras buenas esperanzas, autorice nuestros elogios, diremos desde luego que empezar dando al público en el primer día tres novedades dramáticas en sólo dos teatros, es empezar con muy buenos auspicios" (I, 361b).

El primer gran éxito fue La conjuración de Venecia. El interés suscitado por el drama se vio realzado por el esmero con que fue puesto en escena. Dice Larra: "Seríamos injustos si no hablásemos de la empresa. Muchas veces hemos indicado cuánto debíamos esperar de ella, porque conocíamos personalmente sus recursos; sin embargo, no siempre se nos creía. Apelamos ahora a la experiencia: dígasenos cuándo hemos visto en nuestros teatros ponerse en escena con tal pompa y tal exactitud histórica un drama: este tributo que rinde la empresa, no al nombre del autor - por más que éste le mereciese por sí sólo- puesto que antes de ocupar su alto puesto estaban ya hechos los preparativos, sino al teatro español, nos hace fundar grandes esperanzas [...]. Sabemos que las composiciones originales merecerán iguales atenciones siempre que su naturaleza lo exija" (I, 387a-b). Al escribir esto, Larra estaría pensando en el estreno de su Macias.

Uno de estos artículos de comienzo de temporada (que saldrá a relucir en la controversia con Azcona) es el de Larra sobre $E l$ Colegio de Tonnington. Dos semanas antes se había estrenado otro drama del mismo autor, El verdugo de Amsterdam. No era Ducange nuevo en la plaza: "Víctor Ducange -dice Larra en su nota sobre El verdugo- es conocido ya en nuestros teatros, particularmente por su Jugador. Ya puede presumir quien haya visto este drama, y quien lea solamente el título del presente, el carácter de la obra" (I, 394a). El mismo Grimaldi había montado El jugador en 1828, y más de un lector de Fígaro recordaría el furibundo artículo que le dedicó el primerizo Duende Satírico del Día en uno de sus cuadernos, atacando con sarcasmo al dramón y al romanticismo que pretendía representar: "¡Y que todo esto suceda en Francia, como quien dice en casa del vecino, tabique por medio, y no se haya traslucido nada en esta España!" (I, 16b-17a). En mayo de 1834, el autor del Verdugo le parece un carnicero: "Conmover con sangre no es la obra grande del poeta: un carnicero puede hacer otro 
tanto". Sin embargo ahora está dispuesto a concederle méritos: "No es decir que carezca de méritos $E l$ verdugo: la escena de padre e hija, la de los amantes en el último acto, y alguna otra, son de mucho efecto y tuvieron grandes aplausos". Elogia la actuación de Matilde Diez y en favor de la empresa dice: "Este drama se puso bien en escena, y es lindísima la decoración de nieve del tercer acto" (I, 395b).

La crítica del Colegio de Tonnington es muy positiva. Ducange, según Larra, no emplea aquí la técnica del carnicero: "He aquí otro drama del autor de Treinta años, y acaso de los suyos el mejor. No es la vista de la sangre, no son los horrores y los asesinatos los recursos de su argumento. Un asunto bastante delicado, eso sí, y que pudiera ofender la irritabilidad de los rígidos moralistas, ofrecía un campo lleno de espinas al poeta" (I, 402a). El drama ha gustado, la actuación de Concepción Rodríguez - la esposa de Grimaldi- le parece perfecta; en cuanto a la empresa: "Fue bien puesto este drama en escena, y si bien el partido de la administración pasada de los teatros quiso, como sucede ahora todos los días, ingerir en el final sus parciales demostraciones de desaprobación, la pública indignación triunfó de la hostilidad, y sofocó todo chicheo" (I, 403b). (Chicheo al que alude luego Azcona; cf. infra, p. 67). Por lo que dice Larra, el partido de la oposición iba dispuesto a armar jaleo en todas las funciones. Durante la representación de la ópera Il furioso nell' isola di Santo Domingo azuzaron un perro al escenario: "De aquí hemos inferido -dice Figaroque el partido de la oposición a la empresa, que en todas las representaciones mete su baza, no desaprueba en realidad, no habla, no chichea, sino que ladra" (I, 408b).

La primera representación de ópera fue el 3 de abril con $E l$ nuevo Fígaro, de Ricci. Se armó un escándalo formidable con la presentación de la Sra. Edwige: "No sabemos si canta más y mejor que lo que hemos oído - reseña Figaro-, y si su turbación del primer día o cualquier otra causa externa han podido influir en su desgracia. El hecho es que desde los primeros compases que cantó, se empezó a declarar el desagrado; esto habrá podido contribuir a disminuir sus facultades; nosotros quisiéramos que fuera así, aunque tememos que salga fallido nuestro deseo".

Sin duda, los enemigos de la empresa vieron la ocasión propicia para armar el alboroto, dejando de lado la más elemental caballerosidad: "No contentas por lo visto algunas personas con los chicheos que acompañaban las piezas cantadas por la Sra. Edwige, la saludaron al comenzar el final del segundo acto con desiguales carcajadas y remedos burlescos y desentonados de su canto. La Sra. Edwige, que padecía sin duda profundamente en su interior, no pudo resistir y cayó desmayada en brazos de sus compañeras, sin 
que su estado lastimoso y su desaparición de la escena bastasen (sea dicho con rubor) a desarmar la animosa oposición ni a acallarla rechifla. Merced a la autoridad, concluyó escena tan desagradable con la caída del telón" ( $R E$, núm. 180, 4 de abril de 1934).

Pero el acontecimiento de la temporada de ópera iba a ser la Grisi. Se la esperaba con interés y ya sabemos el entusiasmo con que la recibió Larra. Los artículos a ella dedicados son conocidos. Del primero de ellos, la crítica de I Capuleti ed $i$ Montecchi, no se sabe bien, como el mismo Larra dice, si es "un artículo músico en política o un artículo político en música" (I, 389b) ${ }^{17}$. (Transcribo sólo los pasajes a que luego aludirá Azcona). Los entusiastas comentarios de Larra sobre la belleza de la cantante no suscitaron la menor contradicción. No así otros aspectos de su reseña referentes a sus méritos como intérprete de ópera, sobre todo aquello de que nunca se habia oído cantante mejor en Madrid:

La señora Grissi, sin que queramos ofender la memoria de la expresiva Todi $[s i c]$ y de la profesora Lalande, es indudablemente lo mejor que en Madrid hemos tenido, supuesto que reúne en grado eminente las calidades que separadamente tenian aquellas dos cantatrices, siempre de feliz recuerdo para nosotros, que nunca reconoceremos más partido que el de nuestras impresiones (I, 391b).

Tras I Capuleti ed $i$ Montecchi, Anna Bolena. No puede decirse que fuera un éxito: "el público [...] estaba tan frío y descontentadizo como si le estuvieran gobernando y haciendo feliz, y tan callado y tan de mal humor, como en tiempo de Calomarde; la orquesta estuvo tan discorde y llena de contradicciones, como nuestra legislación" (I, 398a). Según señaló Sánchez Estevan, "entre [las] censuras sobrenadan los elogios a la señora Grissi” (102). A pesar de los defectos de la representación, la Grisi, según Larra, "aumentó su reputación": "Probó que tiene agilidad y ejecución, contra todo lo que algunas personas decían en el particular. Nosotros nos ratificamos en que no hemos acabado de comprender aún en Madrid, cuán preciosa es la adquisición que hemos hecho en esta excelente cantatriz" (I, 399a).

Para entender luego una de las alusiones a Figaro en el artículo de Azcona sobre Anna Bolena transcribo lo que escribió el crítico de la $R E$ sobre la actuación del bajo Botelli:

Fue una gran lástima que el señor Botelli no estuviese esta noche tan feliz como acostumbra; dos o tres veces creímos notar, sobre todo en cierto terceto, que andaba algo reñido con sus compañeros; y aún, si no nos equivocamos, cometió una pequeña dis-

17 Para su intención política véase P. Uluman, Mariano de Larra and Spanish political rhetoric, The University of Wisconsin Press, 1971. 
tracción: antes de concluirse la ópera, y cuando debía dirigirle la palabra la señora Edwige, el señor Botelli, no teniendo más que cantar, pero debiendo continuar en escena, juzgó conveniente salirse bonitamente y marcharse; es decir, que S. M. el señor Enrique VIII, hecho un pretendiente, puso pies en polvorosa como si le siguiera Rodil (I. 399b).

\section{EL "Semanario Teatral"}

La oposición también tenía su órgano. A las tres semanas de comenzar representaciones organizadas por la nueva empresa de teatros (21 de abril de 1834), sale a la calle el Semanario Teatral, periódico de amena literatura. A partir de la sexta edición apareció los lunes y los jueves en fascículos de cuatro páginas que formaban dos entregas diferentes del mismo número semanal.

El hecho de que Sánchez Estevan no pudiera dar con este periódico indica ya su rareza. En la Biblioteca Nacional de Madrid sólo se hallan los núms. 1 (21 de abril, 1834), 2 (28 de abril), 4 (12 de mayo) y 5 (19 de mayo). Aunque Eugenio Hartzenbusch lo cataloga en su repertorio de periódicos madrileños con el núm. 252, la imprecisión con que lo reseña da a entender que sus noticias no eran de primera mano ${ }^{18}$. La colección del Semanario Teatral que se halla en la Biblioteca de la Universidad de Toronto no está completa, pero de los seis cuadernos que la componen, los tres primeros contienen el material que nos interesa para reconstruir este episodio biográfico de Larra: núm. 6, (Ia y 2a entrega, lunes 26 y jueves 29 de mayo de 1834) y núm. 7 ( $1^{\text {a }}$ entrega, lunes 2 de junio) ${ }^{19}$. Parece como si algún contemporáneo de Larra, interesado en el asunto, hubiera colecionado los números pertinentes del Semanario.

Ya sabemos que lo redactaba Agustín Azcona. A Larra le parecía un actor muy malo. No puedo ahora averiguar las veces que Larra se había referido a él cuando, en sus artículos de las temporadas anteriores, criticaba a los actores cómicos indicando el papel que tenían sin decir los nombres. La única vez que alude directa-

18 Hartzenbusch se limita a decir: "Debió principiar en abril de 1834 con dos o tres pliegos de impresión, y salía los lunes de cada semana" (Apuntes para un Catálogo de periódicos madrileños desde el año 1661 al 1870, Madrid, 1894, p. 44).

19 Los otros tres números que se conservan en la colección Buchanan de la Universidad de Toronto son la $2^{a}$ entrega del núm. 7 (jueves 5 de junio); núm. 8, 29 entrega (jueves 13 de junio, por error de imprenta, pues el jueves era día 12); y el núm. 10, $2^{2}$ entrega (jueves 19 de junio). Juntando las colecciones incompletas que se hallan en las dos bibliotecas de España y Canadá, tenemos la serie del Semanario Teatral del núm. 1 al 7 excepto el 3 (del 5 de mayo). 
mente a él es para elogiarlo, aunque el elogio resulta mezquino, como quien dice: "Hasta Azcona lo hizo bien!" En el artículo de Figaro sobre la Mojigata, de Moratín, leemos: "Con respecto a Azcona, es la primera vez que nos ha gustado: creemos que no se puede desempeñar mejor su parte" (I, 342b; el subrayado es mío) . En cuanto a los juicios que aparecen en $R E$ sobre Azcona como director de escena de la ópera, baste esta muestra tomada de la crítica a Chiara di Rosemberg, de Ricci: "Se ha ejecutado tan mal como el año pasado el coro que da principio al segundo acto. La misma impavidez simétrica en la acción de los inanimados coristas; los mismos gritos en los pianísimos. ¿Quién tiene la culpa?, no son los coristas: Si se les dijera lo que tienen que hacer en escena, en la parte mímica, lo harían seguramente, pues no los juzgamos más torpes que los comparsas que vemos en algunas funciones de verso prestarse al movimiento de las más interesantes situaciones" ( $R E$, núm. 88, 23 de agosto de 1833).

En la campaña periodística emprendida por Azcona en el $S e$ manario, el resentimiento contra la nueva empresa que lo había echado a la calle se une al rencor motivado por las críticas de Figaro a sus actuaciones. Ahora el odiado crítico defendía a la odiada empresa.

Los ataques a la situación de los teatros dirigidos por la nueva administración parecen ser la preocupación fija en casi todos los números que hemos podido ver. Las noticias teatrales están salpicadas de pullas. El 30 de abril reprodujo Larra en su Revista Española un texto del Semanario (núm. 2, pp. 4-5) en que se anunciaba la llegada de la Grisi a Madrid el 23 de abril. Se le advertía a la cantante que el público guardaba "la grata memoria de cosas pasadas" y se aludía al desmayo reciente de la señora Edwige:

Lo que importa es que esta nueva cantatriz no se acobarde al oír recitar los triunfos de los que la han precedido; que se lance valerosamente en la arena del proscenio; que luche audaz e imperturbable con la grata memoria de cosas pasadas, y con la aragonesa obstinación de los espectadores actuales; y sobre todo que no tengamos el disgusto de que Romeo, joven, valiente, animoso, "y de acerado yerro revestido", se nos desmaye antes de tiempo, y tengan que acudir capuletos y montescos a sostenerlo, con perjuicio de la ilusión, por el visible daño de la verosimilitud.

Al citar estas líneas, Larra evitó reproducir el párrafo inmediatamente anterior, que terminaba con una alusión personal al crítico, con lo cual indicaba que se daba por enterado, pero que no quería hacer caso. Dice el Semanario: "Si [la Grisi] se conserva en el lleno de sus facultades, respecto de lo cual corren algunas voces poco favorables que creemos suscitadas por el espíritu 
de partido; si acierta a conjurar los recientes recuerdos de otra profesora de primera celebridad [la Tosi], cuyo canto bien bien que no absolutamente spianato era sin embargo, admirable, podrá llevar Romeo al teatro otra tanta gente como ha desterrado Figaro".

Otra noticia teatral del Semanario, que indica los escozores de su redactor, dice: "El público entrevé con desagrado que la mar. cha adoptada por la nueva empresa tienda a privarnos sucesivamente de muchos actores laboriosos y de mérito conocido, a quienes sin duda prepara los económicos honores de la jubilación, o los del ostracismo provincial. La señora Baus, primera actriz más antigua en Madrid, tan recomendable por sus talentos artísticos, aparece muy de tarde en tarde en la escena" (26 de mayo).

El resentimiento de Azcona parece obsesivo. No sólo aprovecha las noticias de miscelánea teatral, sino hasta la cartelera de la semana anterior. Veamos algunas muestras:

Lunes 26.-Cruz: última representación de Anna Bolena, ópera en dos actos de Donizetti; cortada, recortada, apuntada, transportada, estropeada, y tan celebrada como lo denota la primera palabra del anuncio, cuando no contaba aun más que cuatro noches de vida (29 de mayo). Sábado 24.-Príncipe: El colegio de Tonnington, o la Educanda; drama nuevo en seis actos y en prosa, de Ducange, traducido por el señor Bretón, prohibido años pasados por ser cínicamente escandaloso. Lunes 19.-Cruz: No más mostrador, comedia original traducida del francés, en cinco actos y en prosa (26 de mayo).

Unos días antes había aparecido en el Diario del Comercio un artículo contra Larra, diciendo que la comedia No más mostrador no era original, sino una traducción de la de Scribe Les adieux au comptoir. Como es sabido, Larra tuvo que salir a defenderse en un artículo, "Vindicación" ( $R E, 23$ de mayo; I, 400-401). La dudosa originalidad de Larra estaba, por lo tanto, de actualidad y Azcona no desaprovecha la ocasión. Al parecer, en esta época los enemigos le salían a Larra por todos lados.

\section{Los artículos del "Semanario Teatral" relativos a Larra}

Los artículos que se refieren a Larra en esta campaña emprendida por el periódico de Azcona contra la nueva empresa de teatros, son los siguientes: uno sobre Anna Bolena (núm. 6, 26 de mayo, pp. 1-3); un párrafo para reproducir un artículo, publicado originalmente en el Eco del Comercio, sobre el Colegio de Tonnington (núm. 6, 29 de mayo, p. 1); un suelto con el título de "Anécdota" que terminaba con la quintilla que ya conocemos (ibid., 
p. 4) ; un artículo original del Semanario sobre el Colegio de Tonnington (núm. 7, 2 de junio, pp. 1-3).

No sabemos lo que el Semanario diría en el artículo que sin duda dedicó a la presentación de la Grisi con I Capuleti (que tuvo lugar el 19 de mayo; el artículo dedicado a ella en el Semanario debió aparecer en el núm. 3, 5 de mayo), pero no aparecen alusiones a él en ninguno de los escritos con que Ventura de la Vega y Larra contestaron a los ataques de Azcona. Al primer artículo a que se refiere Ventura de la Vega es el dedicado a Anna Bolena. Azcona considera la ópera de Donizetti bajo tres aspectos: "como poema, como partición musical y como espectáculo puesto en acción"; los dos primeros son muy pretenciosos y no atañen al asunto que trato aquí. Interesa, en cambio, lo que dice sobre la ópera "como espectáculo puesto en acción". A Azcona le importaba hacer ver lo malo que era su sucesor en la dirección escénica: "Bajo este aspecto ha sido Ana Bolena la tragedia de Manolo". Se burla de la dirección escénica por el decorado del palacio de Windsor, de la mezquindad del alumbrado, y del mensaje y del movimiento de los personajes: "La distribución de los personajes principales y subalternos es maravillosa, y sus salidas y entradas tan racionales como por los cerros de Úbeda". Critica el peinado, el pañuelo y el vestuario de Ana Bolena, a lo que luego replicará Ventura de la Vega reprochándole su ignorancia para ser juez en tales materias.

Las referencias a Larra en este artículo aluden a su valoración de la cantante por encima de todos los precedentes conocidos en Madrid:

Por lo que respecta a la ejecución, creemos que el decir que la señora Grisi no tiene mérito, sería una blasfemia filarmónica, una injusticia atroz, un delito de lesa razón: y el asegurar que no se ha oído cosa tan buena en los teatros de Madrid es una horrorosa, tremebunda y ostrogoda necedad, únicamente perdonable a los que van a oír la ópera a expensas de bolsillo ajeno, tal vez interesado en que estas gratuitas suposiciones tomen una boga que no tomarán. La señora Grisi ha cantado esta ópera luchando no muy ventajosamente con los respetables recuerdos de la Lalande, hasta cuyo desempeño hay tal cual distancia. Los que ensalzan a la actual prima donna con desmesuradas exageraciones, le hacen más mal que bien, porque el caballero público es un sujeto muy instruido; y como paga de subida para oír menos, no tragará las doradas pildoras de los que se quieren tomar el trabajo de ilustrarle probándole que tres y dos son veinte y siete. De aquí es que la indiferencia, y aun si se quiere el desagrado del público, se aumen ta en razón directa de tan extemporáneos encomios. La señora Grisi hubiera hecho bien en conservar la cabatina del spartito, que es de mucho más efecto: hubiera hecho bien en interesarse algo 
más en las piezas concertantes, marcando un poco menos en varios parajes en que canta sola: hubiera hecho bien en vestirse mejor, particularmente en el acto segundo, porque aquel terciopelo negro con galones dorados, es más bien un paño de tumba para entierros de primera clase: hubiera hecho bien en economizar sus pies y sus brazos, ahorrándonos algunos pasos de galop, muy extravagantes, $\mathrm{y}$ las repetidas posturas en rigorosa cruz que no son poses très belles ni en Madrid ni en Pekín: y sobre todo hubiera hecho grandemente bien en elegir otras óperas que no hubiesen oído en Madrid; porque debe saber, que aunque haya leído que Capuleti $e$ Montecchi no se ha cantado nunca como se está cantando, es falso, lo que se llama absolutisimamente falso. Para juzgar así se necesitan orejas como las de Midas.

Con respecto a lo que Larra había supuesto que era un gazapo filarmónico del bajo Bottelli (cf. supra, pp. 56-57):

El señor Bottelli ha sostenido su buena reputación en el papel de Enrique VIII, evitando en la primera representación una catástrofe anticipada. Cierta persona saltó en el terceto unos cuantos compases: el señor Bottelli, buen profesor y siempre en guardia, se apercibió del salto, y reasumiendo a su voz el dominio del escenario, restableció hábilmente la perdida cuenta secundado por nuestro digno maestro el señor Carnicer, y por los señores individuos de la orquesta. Este servicio importante le ha valido a Bottelli una recriminación, suponiendo gratuitamente cierto periódico que el bajo había faltado, cuando fue el bajo quien cubrió la falta. ¡Bravo, signor Figaro!

Azcona termina su artículo contradiciendo la opinión de Fígaro sobre la orquesta (que "estuvo tan discorde y llena de contradicciones como nuestra legislación"), sobre la Grisi (quien según el actor no tenía nada nuevo que enseñar a los aficionados madrileños) y reiterando la acusación de venalidad barata - jtodos por la entrada gratis! - en un pareado de remate:

La orquesta es fiel intérprete de los pensamientos del autor; pero no basta. Por más que suden gotas gordas no haremos camino. Ha habido, no obstante, quien se hava atrevido a decir que la orquesta no ejecutó bien la sinfonía. Esta es otra, prima hermana de la de Bottelli. No parece sino que algunos se proponen delirar en vez de raciocinar. Y entre tanto oiga Vd. con paciencia que hasta hoy no se ha cantado bien el final del primer acto de Capuleti e Montecchi!

¡Fuerza de una luneta a lo que obligas:

A decir que son blancas las hormigas! 
En el siguiente cuaderno del Semanario (jueves, 29 de mayo), viene el primer artículo en que se ataca al drama de Ducange. Está reproducido, según hemos indicado antes, del Eco del Comercio y como introducción inserta el Semanario el párrafo siguiente:

f́bamos a escribir nuestro artículo, analizando esta composición peregrina que la Revista ensalza: es decir Fígaro, el de la Revista: que los otros periódicos deprimen, y que a nosotros nos parece desatinada y sucia en grado superlativo. Pero reconociendo que no podíamos decir más ni mejor dicho, hemos preferido insertar parte del artículo que se lee en el Eco del Comercio, disponiéndonos a dar en el número siguiente todas nuestras observaciones. Cuando escritores tan apreciables como los del Eco y los del Diario de Comercio hablan en contra, debe comprender el señor Fígaro que está viendo el mundo por un agujero cubierto de telas de araña. Al número próximo, repetimos; allí se le ajustará la golilla en debida forma.

En la última página del mismo número, entre un artículo sobre un juego de prendas en que intervino Napoleón y el anuncio de un nuevo periódico, se podía leer un articulillo muy breve con el inocente título de "Anécdota":

En la noche del 26 del corriente, en que falleció la ópera titulada Anna Bolena, para no volver a resucitar por ahora (así sea y duerma en paz), hubo una concurrencia extraordinaria, por lo poco, si otras lo son por lo mucho. Esto no obstante, encontrábase a nuestra retaguardia cierto poeta, que por su facha debía ser de los que escriben a moco de candil, pero con gongorina malicia; y al caer el telón, terminado el acto segundo, regaló a la difunta el siguiente epitafio:

Y aquí viene, después de los dos puntos, la dichosa letrilla que tanto despistó a Sánchez Estevan, seguida de la exclamación: "¡Si son los demonios!" con que se remata la anécdota.

No parece que Larra se tomara muy a pecho las alusiones del Semanario Teatral. Se limita a replicar burlonamente ( $R E, 30$ de mayo) con una serie de típicos rehiletes que aluden al redactor del Semanario, y a un anuncio del mismo periódico (2a entrega del núm. 6) sobre la publicación de un retrato del tenor Passini, predilecto de la administración anterior. Son los siguientes:

-¿Quién hace ese papel, preguntaba maliciosamente un chusco que leía el semanario teatral? -Un cómico, le respondieron: y es el que ha hecho mejor en toda su vida. -¿Qué tal cómico será?, repuso el chusco. - Se habla de la tardanza extraordinaria del señor Genero, tenor ajustado para estos teatros ¡Sí: lo habrá pasado la empresa a la censura eclesiástica, equivocado entre algunas comedias! 
-El Sr. Passini se acaba de hacer retratar según un periódico de esta corte: hay quien dice que no le falta más que cantar.

- Un elegante decía en el teatro una de estas noches mirando al quinqué que alumbraba realmente poco, "pero señores, estamos a obscuras". -Es noche de ópera, le contestó el que tenía a su lado.

$-\mathrm{Se}$ va a representar il furioso $-\mathrm{Si}$ esta ópera no hace furor, podemos despedirnos de salir ya furiosos del teatro. Dos cosas podemos asegurar que habrá desde luego furiosas: la voz del bajo y el semanario teatral.

-Desde que nos hemos quedado sin Tiempo nuevo diario de la tarde, apenas se oye a los ciegos; de tal suerte que parecen todos segundos tenores.

-Il Furioso, ópera del maestro Donnizetti, desempeñada por las Sras. Edwige y Campos y los Sres. Alexandre, Boticelli, Galdon y Salas, será la primera novedad filarmónica en los teatros de esta corte.

Quien se encargó de contestar directamente a las alusiones del Semanario Teatral fue Ventura de la Vega, otro de los puntales de la nueva empresa y amigo de Larra. El 3 de junio salió a defenderlo en un artículo de la Gaceta de los Tribunales (cit. por Sánchez Estevan, 258-259). Al reseñar el periódico de Azcona, Vega cita las líneas alusivas a Larra con que concluye el párrafo redactado por el Semanario Teatral (cf. supra, p. 62). Leído completo este párrafo introductorio, el contexto de la cita, desconocido para Sánchez Estevan, queda ahora claro para nosotros. Ventura de la Vega se limita a reproducir -apostillando entre paréntesis- las líneas indicadas del Semanario:

También es digno de notarse lo siguiente: Cuando escritores (tránsito del escrito a los escritores), tan apreciables como los del Eco y los del Diario del Comercio hablan en contra, debe comprender el Sr. Figaro que está viendo el mundo por un agujero cubierto con telas de araña.

En otro pasaje del artículo se refiere Ventura de la Vega a la "Anécdota".

En la anécdota, no creyendo personalidad marcada el nombrar a Figaro y decir, no del periódico, sino de los redactores, se particulariza con el Sr. Larra; y puesto que esto vale, diremos que el Sr. Azcona, trabajador del Semanario teatral, se produce necia y mordazmente contra una persona conocida y apreciada justamente por su amenidad literaria, y que personaliza la cuestión, faltando al decoro y respeto que debe todo escritor al público que le favorece, leyéndole acaso sin merecerlo; y finalmente, que ha traspasado los límites prescritos por las leyes y la misma sociedad.

Creemos que para castigar sus culpas y conciliarle el desprecio 
que se merece, basta dar mayor publicidad a la desconcertada quintilla Holoférnica con que termina el artículo en cuestión ${ }^{20}$. Hela aquí para consuelo de los ignorantes y afrenta de los buenos poetas, que no la anatematizan: [aquí reproduce la quintilla].

Nota de la Redacción.-Tenemos barruntos, y aun casi certidumbre, de que esta bien acabada quintilla debió su origen a los macarrónicos engendros de una noche de trípili, en que su autor lució asaz los miserables talentos que le distinguen.

Ahora podemos apreciar todo el alcance de la quintilla y de las demás alusiones personales de Azcona en relación con Larra y la Grisi. Como vemos, se refieren únicamente a los juicios de Larra sobre las representaciones teatrales y para nada dejan traslucir la menor referencia a las relaciones entre el crítico y la cantante fuera del campo profesional. (Lo más grave por ahora parece ser la acusación de venalidad para con la empresa, y, de no haber llevado Azcona sus agravios personales más allá de los artículos hasta ahora referidos, Larra no hubiera ido a desafiarlo). Estas son todas las alusiones del Semanario Teatral sobre el asunto de Larra y la Grisi. Estos son todos "los incidentes de la representación de Ana Bolena". Si hubiera habido el menor rumor, podemos estar seguros - por el calibre de las injurias que luego vamos a leer- de que Azcona no se hubiera callado. A Larra no le escocieron ni -como creía Sánchez Estevan- "los agravios personales que, relacionados con la Grissi, le infería Azcona" (104), ni la quintilla, ni nada de lo publicado hasta entonces por el Semanario Teatral. Lo que Larra ya no pudo tolerar fue la "multitud de alusiones injuriosas y de calumnias" a que luego se refiere el artículo del 5 de junio de la Revista Española, y esto ya no tiene nada que ver con la Grisi.

\section{Las "alusiones injuriosas y calumnias" del actor Azcona}

Recordemos que en el mismo cuaderno del Semanario en que se insertaba la anecdótica quintilla, se le prometía a Figaro, para el número siguiente, ajustarle "la golilla en debida forma", es decir, ponerlo en la picota, por el delito de haber publicado una crítica favorable de El colegio de Tonnington, drama condenado por críticos de otros periódicos. El caso es que en el cuaderno del 2 de

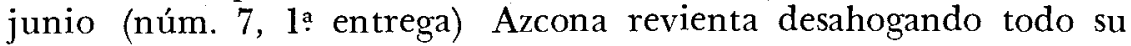
resentimiento en un larguísimo artículo de seis apretadísimas co-

20 Como vemos, el "artículo en cuestión" no es, como creía Sánchez Estevan (102), el que trata sobre el drama de Ducange, El colegio de Tonnington (cf. infra, pp. 65 ss.), sino el breve suelto "Anécdota" (cit. supra, p. 62). Son dos artículos que aparecieron en diferentes números del Semanario Teatral. 
lumnas -casi la mitad de todo el periódico-, titulado "El Colegio de Tonnington". Sólo transcribir los pasajes que nos interesan (los que contienen alusiones a Larra, a Ventura de la Vega y a la empresa) ocupará bastante espacio. Empieza así:

Hay cierto escritorcillo sabandija, entrometido por naturaleza, maldiciente por costumbre, adulador por necesidad, y fabricante de suposiciones por inclinación; foliculario endeble, obligado de patillas, que a favor de humillaciones por una parte, y de insolencias y detracciones por otra, principió a hacer sonar su nombre, de que ninguno se hubiera acordado probablemente, allá en tiempos en que era él uno de los pocos que tenían privilegio y carta blanca para embadurnar de negro los productos de las fábricas de Alcoy y Capellades. Satélite inseparable y asiduo de cierto aspirante a empresario, que con sus cien mil proyectos aeriformes para tomar por asalto los teatros de Madrid, pasando a degüello la mitad de la guarnición, ocasionó al Excmo. Ayuntamiento en dos años una pérdida de treinta mil duros, había encontrado en estos negocios mina fecunda para sus chafalditas picarescas. Ni la administración, ni sus representantes, ni los actores, ni ninguno de los empleados o dependientes, inclusos los comparsas, nadie que no perteneciese a la pandilla consabida estaba libre de sus tiros; quedando siempre impune, porque los ofendidos debían hacer para contestar gastos considerables y mortificantes gestiones, resultando, aun en este caso, sus defensas desprovistas del interés y la fuerza que comunica la oportunidad. Hollando con atrevida planta todas las reales disposiciones que prohibían justamente las siempre odiosas personalidades, atacaba reputaciones, hostilizaba insidiosamente a cuantos le eran designados por el dedo del amo, como objeto sobre los cuales debía esgrimir una pluma de hierro, mojada en vinagre y en hiel; esperando sin duda que después del triunfo le nombrasen por lo menos portero honorario de uno de los teatros de la Corte. ¡Pobre mueble!

Hoy que a Dios gracias está más expedito el camino para contestar pronta y enérgicamente a quien insulta, se mantiene nuestro hombre en cierto modo a la capa; pero, sin dejar sus viejas mañas, aprovecha tal cual ocasión de morder, y encomia hasta las nubes a quien le paga, o le ha prometido por lo menos tenerle presente en mejor ocasión. Esto no es del caso: sin embargo, servirá de aviso.

Baste de introito, y vamos a Fígaro. Se le prometió en la $2^{a}$ entrega de nuestro núm. $6^{\circ}$ una catilinaria, y estamos en el caso de escribirla. ¿A quién sino a Fígaro se le ocurriría meterse a abogado de pleitos perdidos? ¿Conque el colegio de Tonnington es un buen drama? ¿Conque es el mejor del célebre Ducange? ¿Conque los chicheadores eran los partidarios de la antigua administración? ¿Conque les hizo callar y ahogó sus chicheos la indignación del público? Discurramos por partes.

El drama en cuestión es uno de los muchos que, prostituyendo bajamente la poesía dramática, han sido abortados por las celebri- 
dades del Boulevard de París para halagar las pasiones fuertes y desenfrenadas de los espectadores: para desmoralizar al público que concurre, familiarizándole con todo género de vicios, los cuales reciben cierto agradable barniz con el acompañamiento de flautas, violines, luces, telones y trajes: para labrarse por extraordinarios medios una reputación verdaderamente usurpada, y a la cual no es dado aspirar de otra manera: pareciéndose en esto ellos y Fígaro al famoso malhechor que abrasó en Efeso el templo de Diana. Los historiadores modernos deberian proceder con emprendedores semejantes, como con el atrevido incendiario procedieron los antiguos; pero en este siglo, que no sin razón ni gracia ha llamado un filósofo el siglo de la cerveza, hasta de la espuma se hace caso.

Sigue el artículo con una exposición interminable del argumento del drama en la que se hacen resaltar burlonamente las incongruencias, aberraciones e inmoralidades acumuladas por Ducange ${ }^{21}$ :

Sir Love es un simple de capirote, forrado de tonto, con sus puntas y collares de bendito, puesto que no acierta a columbrar por entre los agasajos de Milord Duque tan sospechosos, una intriga que se está revelando por sí sola, sin que para reparar en ella se necesite gran capacidad de entendimiento. ¡Es una friolera! Proponerle a una pobrete muchacha bonita que no conoce, y el grado de coronel si se casa y todo de parte de un gran personaje, y todo por la mediación de otro personaje, y recibir orden para marchar a la hora crítica de ... Vamos, es preciso ser Ducange para crear estos originales caracteres dramáticos: es necesario ser Love para tragar tales maromas; y es indispensable ser Fígaro para asegurar que esta linterna mágica es una maravilla $[. .$.$\rceil . Escritores$ públicos, dignos bajo todos aspectos del mayor aprecio, han criticado el Colegio de Tonnington, desdeñando emplear su pluma en analizarlo. Se han hecho por ellos tantas y tan oportunas reflexiones, que creemos suficientemente ilustrada la materia, mucho más después de la vindicación de los señores editores del Eco del Comercio, inserta en el número 30, contestando a la Gaceta de los Tribunales, cuyo redactor encargado de la sección de teatros ha puesto en prensa su entendimiento para ver si sería posible exprimir una razón, un fundamento que sirviese de base a la defensa

21 El argumento es éste: Milord Duque, importante personaje de la corte de Enrique VIII, quiere seducir a Adela, alumna del colegio de Tonnington. Para que salga del colegio decide casarla (ayudado por la tutora de Adela) con un joven protegido suyo, sir Love. E1 seductor consigue que asciendan a coronel a sir Love y que reciba la orden de partir inmediatamente después de la ceremonia nupcial, antes de que pueda consumarse el matrimonio. El malvado fuerza a la recién casada. Un amigo informa al marido de su deshonra; éste regresa y encuentra a Adela en estado de locura, recluida en su antiguo colegio. Reconoce a su esposo en un momento de lucidez y muere en sus brazos. 
de tan espantable mojiganga [...]. En cuanto a los chicheadores, partidarios de la antigua administración, debe V. saber, señor Fígaro, que no ha hablado con exactitud. Hace algún tiempo concurrian, es verdad, chicheadores partidarios de una administración que estaba en pleito; hoy estos chicheadores se han convertido, claro está, en panegiristas, venga o no venga a cuento el panegírico: la antigua administración ni pagó aplausos para sus obras, ni menos promueve o paga gritas para las que ahora se representan. Si hay chicheadores para lo desatinado que día por día se tiene la candidez de presentarnos, no los busque V. en ningún partido de administración fenecida: búsquelos, sí, en la indignación pública, en la sensatez de una concurrencia amiga de la delicadeza en el teatro, y enemiga de las absurdas intentonas de los que le profanan. Búsquelos V. entre las personas que se sacrificarán con gusto por una racional libertad odiando con igual firmeza la licencia y desórdenes bacanales, propios sólo de lupanares en que brillan el oro y las maderas de América, o de zahurdas en que las debilidades y vicios de la especie humana adquieren más asqueroso colorido entre guiñapos sucios y fétidos andrajos. En todas estas clases encontrará V. chicheadores sempiternos que tronarán contra las injurias que se hacen a la moral pública, porque todos los hombres estamos cortados por una misma tijera en esta nación pundonorosa a la par que galante, que se Ilama España; y crea V. que si no hay un espectador que no se sienta dispuesto a abusar del poder en la posición de Milord Duque, tampoco hay uno que sin hacer traición al testimonio de su conciencia, aplauda con descarada frente lo que nosotros criticamos. V. mismo, y el que ha escrito en la Gaceta de los Tribunales, encontrarán entre lo que sienten y lo que han dicho una enorme diferencia. Al que escribió en aquel periódico le disculpamos no obstante, porque le reconocemos tan complaciente, que a veces por complacencia generosa, nada más, es capaz de sacrificar el crédito bien establecido de su ilustración: en V. que no suponemos ni la ilustración ni la complacencia que en aquél, vemos únicamente el empeño de defender no una doctrina, no un sistema, sino un interés de encargo; y no extrañaríamos que por esta misma razón defendiese V. lo contrario mañana.

Luego se refiere Azcona brevemente a la ejecución: "son tantos y tan notables los defectos de la dirección escénica que saltan a los ojos; mas por ser ya este artículo demasiado largo no queremos señalarlos". Señala que el papel de la protagonista desempeñado por la esposa de Grimaldi, no le correspondía por la edad: "Ia señora Rodríguez no está ya en el caso de hacer las niñas". Y termina el artículo -realmente demasiado largo- contestando al primer rehilete de la serie publicada por Figaro (cit. supra, pp. 62-63).

Por lo tocante a cierto bota-fuego figaresco, que se lee en la Revista de 30 del pasado, y del cual consta que este periódico lo 
redacta un cómico, debemos manifestar que así es la verdad; pero reconociendo la maligna y solapada intención con que allí se escribe la palabra cómico para llamar sobre ella el desprecio público, es de nuestra obligación añadir que ningún actor hace escritura de ser ignorante en materias literarias.

De nuevo fue Ventura de la Vega quien se encargó de responder a todas estas injurias. Ya vemos que no era, como pensaba Sanchez Estevan, que el redactor de la Gaceta de los Tribunales no se diera por satisfecho con su andanada del 3 de junio referente a la "anécdota", sino que este furibundo artículo del día siguiente ${ }^{22}$ se debe a nuevos motivos que ya no eran para tomar a broma. Por eso comienza diciendo: "Hasta ahora la redacción de la Gaceta de los Tribunales se había propuesto lanzar únicamente tal cual burlona chanzoneta al Semanario Teatral, por no creer que merecía mayor importancia un periódico vergonzante, órgano de los impotentes graznidos de un partido humillado". Pero la broma no cabe ante la indignación que al redactor le producen los torpes ultrajes dirigidos contra su compañero y amigo, asqueado además por la mancha con que el libelo ha ensuciado la nobleza de la imprenta. Desenmascara al redactor del Semanario exponiendo sus fracasos y disparates como actor, como director de la ópera y como traductor, evidentes razones de la renovadora empresa para no contratarlo. Cualquiera podría juzgar, según Ventura de la Vega, que un tipo de tal calaña no estaba en el caso de insultar a un literato tan prestigioso como Figaro.

En el contexto de la disputa se ve claramente cómo las cuestiones personales en ella implicadas derivan de conflictos profesionales. El secreto -dice Ventura de la Vega- es el empeño de Azcona en desacreditar a la empresa:

Llegó la nueva empresa, y convencida de su imbecilidad, tanto para director como para actor, determinó no ajustarlo, y he aquí al Sr. Azcona en la calle. ¿Qué hará el Sr. Azcona? Un periódico. ¿Cómo se llamará el periódico? Semanario teatral. ¿De qué tratará? Claro está: de desacreditar a la empresa que le ha quitado el pan; de hablar mal de cuanto ha hecho, hace y piensa hacer, sin examinarlo, sin darle a sus críticas, siquiera por propio interés, un colorido de imparcialidad. He aquí el secreto.

Para refutar las acusaciones de Azcona, Ventura de la Vega se atiene a las actividades de Larra como escritor, pues a ellas aludían las injurias del cómico, que lo había acusado de crítico ignorante y vendido al mejor postor. Las relaciones amorosas de Larra no habían salido a relucir ni afectaban al pleito. Lo habrían afec-

22 Apud Sánchez Estevan, 259-261. 
tado, en cambio, si en ellas hubiera estado envuelta la Grisi, la única alusión a ella en este artículo de Ventura de la Vega es sobre el aspecto profesional, a la incapacidad de Azcona para "criticar el peinado y adornos de la Sra. Grissi en Ana Bolena, que está fiel y exactamente copiado del retrato de dicha reina que existe en Londres y del que hemos visto copia; como también burlarse del pañuelo que sacaba en la mano, como si Ana Bolena hubiera de sonarse con los dedos".

La actitud que adoptó Larra fue evitar verse enredado en la disputa $e$ ir directamente a exigir a Azcona una retractación. Este puso condiciones, pero Larra exigía una retractación incondicional. Como tampoco pudo conseguir del cómico "ninguna otra especie de satisfacción" que pudiera vindicar su honor, según las normas que por aquella época obligaban en tales lances, a Larra no le quedó más remedio -y como último recurso- que acudir a los tribunales para querellarse contra el Semanario Teatral. La Revista Española, en su número del 5 de junio, dio cuenta de todo esto en el artículo ya mencionado "Personalidades" ${ }^{23}$, escrito sin duda por el propio Larra, en el que resume de la conversación mantenida con el actor. Es el artículo que comienza así:

En el número 7 del Semanario teatral, periódico de amena literatura, que se publica en esta Corte, vimos un artículo titulado El Colegio de Tonnington. Multitud de alusiones injuriosas y de calumnias degradantes para quien las ha escrito, dirigidas a uno de los redactores de la Revista Española, ya solapadamente, ya a cara descubierta, nos impidieron tomar parte en cuestión tan indecorosa. ¿Cómo responder a proposiciones que de ninguna manera pueden ser de la jurisdicción de la literatura ni de la polémica periodística? El redactor D. Mariano José de Larra, a quien era el artículo dirigido, no creyó el asunto digno de embadurnar con él las columnas de un periódico que se jacta de manifestar constantemente al público el respeto a que es acreedor. Creyendo que éste no podía ser sino un asunto personal, se dirigió el 3 del corriente a casa del Sr. Azcona, editor del Semanario teatral, a las cuatro de la tarde, presumiendo que era la más a propósito para encontrarle...

Después no volvemos a encontrar nada más escrito sobre el asunto, salvo una alusión de Larra en un comunicado enviado a La Abeja, a principios de octubre del mismo año, para responder a un comentario aparecido en ese periódico sobre su salida de la Revista Española para entrar en El Observador: "Dos veces me he visto acometido. Una literariamente, y respondí breve, seria y literariamente. Otra en términos insultantes, y traté de dar la única contestación que siempre daré a insultos personales" (ibid, p. 127).

$\supseteq 3$ Cf., Sánchez Esteban, 261-263. 
La primera se refiere a la acometida del Diario del Comercio poniendo en duda la originalidad de su comedia No más mostrador; la segunda, a los ataques de Azcona. Como sabemos, los dos incidentes ocurrieron por el mismo tiempo y están relacionados con su vida profesional en el teatro, como autor y como crítico. Larra los saca a relucir cuando tiene que volver a defenderse, esta vez ante insinuaciones que parecen afectar su condición de periodista político ${ }^{24}$.

\section{EL Verano DE 1834}

Según Sánchez Estevan, "el verano de 1834 parece que fue de crisis en la existencia de Larra, cuyo curso principió a torcerse" (94). F. C. Tarr (art. cit., p. 103) llama a aquel verano "the dread summer of 1834". Se inicia entonces la crisis que culmina en su viaje al extranjero en la primavera del año siguiente ${ }^{25}$.

24 En cuanto a las relaciones de Larra con Grimaldi, director artístico de la nueva empresa, nuevamente salieron a relucir dos años más tarde, en octubre de 1836, en circunstancias muy críticas que a F. C. Tarr le parecían semejantes a las del verano de 1934 (art. cit., 106). Véase del mismo autor "Reconstruction of a decisive period in Larra's life (May-November, 1836)", $(H R, 5,1937,1-24)$. En una carta dirigida al editor del Castellano explica Larra, retrospectivamente, sus relaciones con el empresario: "Como parece que al llamarme amigo del señor Grimaldi en un artículo en que a éste se le denigra se me quiere hacer agravios, hago presente a usted que mis relaciones con el señor Grimaldi han sido siempre puramente teatrales, al teatro debieron su origen; como director de escena le he debido no pocas atenciones: a él le debí que mis primeros ensayos, buenos o malos, viesen la luz, y que el drama titulado Macias, al que yo daba toda la importancia que un autor da a sus obras, fuese representado y ensayado con esmero singular. De estas atenciones nació esa amistad, amistad que nada tiene que ver con la política, en la cual me considero harto poco importante para mezclar en ella mis intereses o los actos de mi vida. La política sincera no impedirá ser agradecido" (apud C. 45 Burgos, op. cit,, p. 191). Cuando Larra escribió estas líneas hacía poco que, a consecuencia del levantamiento de la Granja, había visto anulada su acta de diputado por Ávila, antes de tomar posesión. Se había presentado a las elecciones como candidato gubernamental del ministerio moderado de Istúriz y, ahora, con los progresistas en el poder, se ve obligado a defender su liberalismo al reconocer su amistad con Grimaldi.

25 Así resume el crítico norteamericano (art. cit., p. 103) las condiciones personales (profesionales, familiares, amorosas) y públicas (políticas y sociales) en que se desenvuelve la vida de Larra en aquel fatídico verano: "In the summer of 1834 there begins a series of complications which lead directly to the crisis of the winter of 1834-35 and the fuga of the following spring. Although the concrete details are in many instances lacking, the general picture seems clear enough. The high hopes which he, in common with many Liberais, had placed in Maria Cristina and in Martínez de la Rosa changed to bitter disappointment and open hostility. The liberal cause seemed seriously menaced not only by the victorious Carlists in the North, but by the govern- 
En este sombrío panorama se sitúan los acontecimientos que hemos referido. Reducidas a sus justas dimensiones las referencias a la Grisi, los ataques de Azcona contribuyen a ensombrecerlo. Afectan directamente la vida profesional de Larra como crítico teatral pero debemos considerarlos en el conjunto de su situación vital.

En sus artículos, el teatro, la literatura, las costumbres y la política son dimensiones de una misma realidad considerada desde una perspectiva crítica y renovadora. Larra veía en la reforma del teatro un aspecto del progreso general de la sociedad. Por ello podemos suponer que, para el crítico, los ataques de Azcona serían expresión de quienes, oponiéndose a la labor renovadora de la nueva empresa, pretendían mantener el teatro en el mismo estado de estancamiento en que se hallaba durante el régimen absolutista, al mismo tiempo que veía amenazada la causa liberal tanto por los carlistas que triunfaban en el Norte, como por el gobierno de Martínez de la Rosa que detenía la revolución política. Los mismos artículos teatrales le sirven para atacar al gobierno mediante alusiones satíricas ${ }^{26}$.

La luz en este verano de 1834 no fue tanto la Grisi como la ilusión de ver renovada la escena madrileña por el impulso de una empresa teatral a la altura de los tiempos. Pero las ilusiones de Larra siempre se desvanecen. A los dos años, la empresa tuvo que pedir la rescisión del contrato que tenía un término obligatorio de tres años, y voluntario de cinco. En dos artículos aparecidos en El Español el 1\% de marzo y el 18 de abril de $1836^{27}$, Larra hizo un balance final de la actuación de la empresa. Las causas a que atribuye su poca fortuna se deben a la realidad social del país que

ment at home. An epidemic of cholera ravaged the capital, all social life was suspended, and even the theatres came within an ace of being closed. $\mathrm{He}$ is separated from his wife, Dolores has fled Madrid, and the only bright spot to relieve the gloom and the boredom was the opera singer Giuditta Grisi". Sigue fragmento cit. supra, nota 8.

26 Véase P. L. Ullman, op. cit. Por ejemplo, en el último artículo dedicado a la Grisi, el 20 de septiembre, sobre la representación de la ópera de Bellini, La Straniera, el párrafo inicial se refería tanto a la cantante como a la política de Martínez de la Rosa: "El saber dejar el campo oportunamente es hacer eterna e inviolable para siempre la fama adquirida; el querer consolidarla cuando no puede ir más allá en guerra, en política, en literatura, en artes, es el cuento del que estando bueno se murió por querer estar mejor" (I, 440a).

27 "Teatros" (II, 157-160) y "Teatros y algo más" (II, 201-203). En el segundo artículo, Larra considera que "si en punto a decoraciones y comedias [la empresa] supo oportunamente abrir la mano, la cerró en cuanto a actores, y a cambio de economías casi insignificantes, no vaciló en deshacerse de algunos utilísimos". Se refiere, entre otros, a Antera Baus, Samaniego y Bravo, Noren, Montaño y Valero $(201 b-202 a)$. 
obstaculiza todos los aspectos de su desarrollo: "si se tiene presente que [la empresa] ha tenido que luchar con las cargas que abruman los teatros, con la turca costumbre de reservarse la autoridad localidades en los coliseos a su placer, con el cólera morbo, con la guerra civil, con la animación de las cuestiones políticas que alejan los ánimos del teatro, y hasta con la poca afición y escasos medios pecuniarios del público, fuerza será confesar que ha hecho más de lo que humanamente se podía exigir de cualquiera empresa común en semejantes circunstancias" (II, 202b) ${ }^{28}$.

Por encima de la anécdota en la biografía de Larra, los acontecimientos aquí expuestos constituyen un episodio significativo que, puesto en el conjunto de la situación histórica de la España del momento, nos revela aspectos de la organización del mundo teatral madrileño en una época en que el teatro español trataba de renovarse por los nuevos cauces del romanticismo ${ }^{29}$.

José Escobar

Glendon College, York University.

28 Sobre las dificultades de la empresa en el verano de 1834, causadas por el cólera morbo y la falta de protección por parte del Gobierno, véase el artículo "Teatros" en RE, núm. 286, $1^{\circ}$ de agosto de 1834.

29 Parte de este trabajo se basa en investigaciones que pude llevar a cabo en la Biblioteca Nacional y en la Hemeroteca Municipal de Madrid, gracias a la generosa ayuda económica del Canada Council al que expreso aquí mi agra. decimiento. 